Journal of Patient-Centered

Volume 5

Issue 4 - Patient Self-Management

Article 8

$10-29-2018$

\title{
Problems Experienced in the Second and Third Months After Discharge From a Heart Failure-Related Hospitalization
}

Joan S. Grant

Lucinda J. Graven

Follow this and additional works at: https://aah.org/jpcrr

Part of the Cardiology Commons, Cardiovascular Diseases Commons, Dietetics and Clinical Nutrition Commons, and the Other Nursing Commons

\section{Recommended Citation}

Grant JS, Graven, LJ. Problems experienced in the second and third months after discharge from a heart failure-related hospitalization. J Patient Cent Res Rev. 2018;5:311-6. doi: 10.17294/2330-0698.1628

Published quarterly by Midwest-based health system Advocate Aurora Health and indexed in PubMed Central, the Journal of Patient-Centered Research and Reviews (JPCRR) is an open access, peer-reviewed medical journal focused on disseminating scholarly works devoted to improving patient-centered care practices, health outcomes, and the patient experience. 


\title{
Problems Experienced in the Second and Third Months After Discharge From a Heart Failure-Related Hospitalization
}

\author{
Joan S. Grant, PhD, RN, ${ }^{1}$ Lucinda J. Graven, PhD, MSN, ARNP2 \\ ${ }^{1}$ University of Alabama at Birmingham School of Nursing, Birmingham, AL; ${ }^{2}$ Florida State University College of \\ Nursing, Tallahassee, FL
}

\begin{abstract}
The purpose of this study was to identify high-priority problems experienced by individuals during the second and third month after discharge from an acute care facility for heart failure. This descriptive, exploratory study, an extension of a previous analysis that examined high-priority problems in the first month, comprised 19 participants who were assigned to an intervention group that received a randomized, 12-week-pilot coping partnership (COPE-HF) intervention. A trained research nurse provided the intervention, and participants used a standard list to identify high-priority heart failure-related problems. Quantitative and content data analysis was conducted. While the highestpriority problem continued to be managing their treatment regimens, the frequency of this problem lessened by week 12. Comorbidities emerged as a new problem in managing heart failure treatment and symptoms. Coping emerged as a new problem, as individuals with heart failure dealt with the impending morbidity of their diagnosis and how it would affect loved ones. Resource issues (ie, financial, social) became more prevalent for individuals with heart failure as potential and actual resources were depleted. Health providers should develop strategies to address these problems to improve outcomes in individuals with heart failure. (J Patient Cent Res Rev. 2018;5:311-316.)
\end{abstract}

Keywords $\quad$ heart failure; problems; postdischarge; self-management; home care; hospitalization

$\mathrm{H}$ eart failure (HF) affects 26 million people worldwide. ${ }^{1}$ Despite treatment advances, individuals with heart failure (IHF) continue to have high hospital readmission rates in the United States. ${ }^{2}$ Research indicates IHF experience various problems during the first month after a HF hospitalization. ${ }^{3}$ Multiple HF symptoms (eg, fatigue, dyspnea on exertion, edema) $)^{4-5}$ and a multifaceted treatment regimen (eg, numerous medications, a low sodium diet, and daily weights) often impact activities of daily living and self-care. ${ }^{6} \mathrm{IHF}$ experience psychosocial

Correspondence: Joan S. Grant, PhD, RN, University of Alabama at Birmingham School of Nursing, 1701 University Boulevard, Birmingham, AL 35294-1210 (grantj@uab.edu) problems (eg, depressive and negative emotions and moods) as well as financial issues. ${ }^{3}$ Inadequate social support, ${ }^{7}$ social isolation, ${ }^{8}$ and diminished relationships with family members also are problematic. ${ }^{3}$ Yet, little is known about whether these problems change over time.

Knowledge of how HF problems evolve may aid development of interventions aimed at reducing hospitalizations in IHF. Thus, the purpose of this study was to identify high-priority problems experienced by IHF during the second and third months following hospital discharge for HF.

\section{METHODS}

\section{Design, Participants, Setting}

This descriptive, exploratory study is a secondary analysis of data collected from IHF randomized to the intervention arm $(\mathrm{N}=19)$ of a 12-week-pilot 
randomized controlled trial. Detailed description of the parent study has been published elsewhere. ${ }^{3,9}$ Hereafter, information pertinent to the current study methods is presented.

\section{Instruments}

Self-reported sociodemographic and clinical information were collected using a researcherdeveloped survey. A data form identified participant identification numbers, the intervention week (ie, 6-12), problems experienced by IHF, and relevant contextual information.

\section{Procedure}

Following institutional review board approval, recruitment, and random assignment, those assigned to the intervention group identified highest-priority HF problems. During weeks 6-12 of the intervention, IHF participated in biweekly telephone contacts with a trained nurse interventionist. During these contacts, IHF sorted a set of 7 empirically based cards to identify both current and new high-priority problems since the last contact. ${ }^{10,11}$ Both problems and their priority were collected on a data form during each contact by the nurse interventionist or trained research assistant.

In ensuring data credibility, the nurse interventionist and a trained research assistant randomly listened to telephone contacts, comparing information recorded on the data form and problems identified by IHF. Accuracy of identified problems was confirmed by IHF at the beginning of subsequent contacts before identifying any new priority problems. Extensive field notes were taken during contacts to add understanding and context to problems.

\section{Statistical Analysis}

Demographic data were analyzed via descriptive statistics using SPSS Statistics 22.0 (IBM Corporation, Armond, NY). Quantitative and content analyses were used to identify high-priority problems. Field notes identifying problems and contextual information were independently analyzed and coded by two content experts. Differences were discussed until consensus was achieved on the final problem list. Two other content experts randomly analyzed problems and field notes further for accuracy.

\section{RESULTS}

The IHF study population had a mean age of 61.0 (standard deviation: 14.5) years, was mostly unmarried $(\mathrm{n}=13,68.4 \%)$, and comprised mostly high school graduates $(n=13,68.4 \%)$. More than half were Caucasian $(\mathrm{n}=11,57.9 \%)$ and male $(\mathrm{n}=11,57.9 \%)$. Usually, 1-2 people lived in the home with the IHF $(\mathrm{n}=11,57.9 \%)$. Most participants had a diagnosis of HF for less than 1 year. More participants were deemed New York Heart Association Class I-II ( $\mathrm{n}=13,68.4 \%)$ than Class III-IV HF ( $\mathrm{n}=6,31.6 \%)$.

Similar to the first month, ${ }^{3}$ problems experienced by IHF were interrelated and influenced other problems. Table 1 identifies the frequency of high-priority problems reported in the second and third month.

Table 1. Frequency of Weekly Problems Reported in Second and Third Month Postdischarge

\begin{tabular}{lcccc}
\hline Problems & Week $\mathbf{6}$ & Week 8 & Week 10 & Week 12 \\
\hline Managing treatment regimen & 18 & 15 & 14 & 8 \\
Managing heart failure symptoms & 10 & 6 & 7 & 3 \\
Completing daily activities & 6 & 5 & 5 & 3 \\
Experiencing negative emotions and moods & 4 & 5 & 5 & 3 \\
Managing comorbidities* & 3 & 3 & 3 & 3 \\
Difficulty in coping & 6 & 2 & 3 & 0 \\
Inadequate resources & 3 & 2 & 2 & 2 \\
Interpersonal/social issues & 2 & 2 & 0 & 0 \\
\hline
\end{tabular}

*In conjunction with heart failure treatment plan. 


\section{Week 6}

Compared with the first month, during which HF symptoms were patients' primary concern, ${ }^{3}$ managing their own treatment regimen was now the highest priority. Issues such as fluid management and remembering to weigh and $\log$ daily weights were more prevalent. Some IHF had difficulty understanding weight fluctuations and when to notify their health provider of significant changes, while others still needed to purchase a scale. Regarding dietary issues, IHF who lived with relatives were hesitant to ask for assistance with their "specialized diet" due to higher food costs and increased efforts needed to find recommended foods.

The problem HF symptoms was now the second highest priority, with similar symptoms (eg, extreme fatigue) experienced as in the first month. ${ }^{3}$ However, heat intolerance was now a significant issue, particularly when exercising during the summer months. Some IHF complained of dizziness/lightheadedness in relation to activity and heat exposure. Symptoms associated with comorbidities (eg, diabetes, muscle stiffness) emerged as a new issue, added to treatment complexity, and impacted daily activities. Carrying out daily activities remained high priority, now ranking third, yet problems remained consistent with those identified in the first month. ${ }^{3}$

Difficulty coping emerged as a new problem. Some IHF finally understood the implications of HF, whereas others were "hoping this was all a misdiagnosis." Others reported uncertainty and fear of the future. Some IHF experienced additional stress because their spouses were not coping well with the HF diagnosis. Activity intolerance and inadequate social interactions were other stressors. Financial stress also occurred for some when denied either disability or Medicaid.

Negative emotions and moods, inadequate resources, and interpersonal/social issues remained problems for a few IHF. At times, moods were "like a roller coaster going up and down." Finances continued to be problematic, with IHF visiting food banks to obtain lower-sodium foods and attempting to get free medication. Food stamp approval occurred for some, while other IHF waited to be notified about financial assistance (eg, Medicaid). Monies were needed to pay copays and HF-related expenses, causing anxiety. New interpersonal/social issues emerged, with lack of support prevalent. IHF now recognized their lack of social activities and support from family members who chose not to invite IHF to join events due to frequent HF symptoms and activity intolerance.

\section{Week 8}

Managing their treatment regimen, dealing with HF symptoms, completing daily activities, and experiencing negative emotions and moods remained high-priority problems. As a new issue, IHF appeared to stop taking daily weights during holidays, especially if traveling. Problems reinitiating dietary adherence and fluid restriction also emerged now. While overall HF symptoms decreased, overwhelming fatigue and lack of energy continued to impact family and social activities as well as work. Yet, some IHF had to return to work despite these symptoms. Intermittent shortness of breath, tightness in the chest, and angina caused anxiety because IHF thought they were having an exacerbation of HF.

Comorbidities (eg, severe arthritis) continued to impacted daily behaviors, while feeling "down" and "blue" regarding their future mortality encouraged IHF to ignore their treatment plan (eg, avoiding smoking). Though less prominent now, problems with difficulty coping, interpersonal issues, and inadequate resources remained. Some life events occurred (eg, dying of close friends/family), resulting in coping issues and reminding IHF of their own mortality. IHF also now chose to avoid talking or socializing with friends because of depressive symptoms, instead making "light conversation." To address inadequate resources, some IHF searched for supplemental insurance or neighborhood clinics to assist with their medical care.

\section{Week 10}

Treatment plan continued to be the most problematic, now with IHF reporting a decreased appetite and difficulty maintaining their exercise regimen due to extreme heat (ie, summer months), but cooling hats were beneficial. Some IHF exceeded fluid restrictions due to increased thirst in the heat. Dietary adherence continued to be a problem, with some IHF following very little of their dietary plan and others requesting assistance to "get back on track." 
HF symptoms continued to plague IHF, with some becoming distressed because of continued tiredness and fatigue despite following their treatment plan. Completing daily activities and negative emotions and moods remained problems, with comorbidities still interfering with daily activities. IHF also reported high anxiety and irritability, often exacerbated by boredom. Like previous weeks, problems with inadequate resources and difficulty coping continued. A significant new concern was future financial security, which impacted emotional well-being. For those who received assistance, their mood improved, with one participant stating "resources have made all the difference." A few IHF had difficulty coping with stress related to obtaining necessary documentation for employment activity restrictions (eg, moving heavy boxes) and carrying out family activities while fatigued or tired.

\section{Week 12}

During week 12, IHF experienced a significant reduction in the overall number of problems. Adhering to and managing their treatment plan was still the top problem, but less frequent. Gaining weight was an incentive to record daily weights, and losing weight reinforced exercising. Often negative emotions and moods impacted treatment components, with IHF perceiving they did not need to change life patterns (eg, dietary changes, exercise) because they expected no improvement in their HF. HF symptoms, along with completing daily activities and comorbidities, also remained consistent issues. Problems with inadequate resources were mostly resolved, or perceived resources were exhausted.

\section{Serendipitous Findings}

Reflecting the previously reported parent study $(\mathrm{n}=66),{ }^{12}$ participants assigned to the intervention $(\mathrm{n}=19)$ reported fewer hospitalizations $(5.6 \%$ vs $12.5 \%$ and $27.3 \%)$ and emergency room visits (5.6\% vs $8.3 \%$ and $27.3 \%)$ than those in the attention $(n=24)$ and control $(\mathrm{n}=23)$ groups, respectively, over 3 months.

\section{DISCUSSION}

Although many problems faced by IHF were similar to the first month, ${ }^{3}$ new problems emerged during the second and third months after hospital discharge. Regarding their treatment regimens, dietary regimens waxed and waned, with some IHF questioning the importance of adhering to dietary and fluid restriction recommendations given their poor prognosis. Yet, data are unclear as to the safety and efficacy of restricting fluids, with some evidence indicating routine restriction may be unwarranted unless IHF have pulmonary congestion or decompensated HF. ${ }^{13,14}$

Comorbidities emerged as a new problem in managing HF treatment and symptoms. For example, different glucose-lowering agents affect HF outcomes, ${ }^{15,16}$ while pulmonary disease, diabetes mellitus, and obesity tend to increase morbidity and mortality risk in both IHF with a preserved or reduced ejection fraction. ${ }^{17}$

Coping was reported to be a new problem, as IHF dealt with the impending morbidity of their diagnosis and how it would affect loved ones. Persistent if less common problems, such as activity intolerance, interpersonal and social issues, inadequate resources, and uncertainty of the future, also were present. Past studies agree with these findings, reporting significant life changes, social isolation, future uncertainty, and the inevitability of disease and death as HF-related issues. ${ }^{18-20}$ In contrast to the first month, ${ }^{3}$ resource issues (ie, financial, social) became more prevalent. Finances were exhausted for some and impacted treatment plans.

While we feel important information was gained, this study had weaknesses such as limited generalizability from a small sample. Still, findings offer several considerations for practice implications. Frequent assessment of treatment adherence and HF symptom management are needed to support physiological stability. Empirical data indicate the importance of education regarding adherence to the heart-healthy diet and medication to lessen risk of readmission and improve quality of life. ${ }^{21}$ Literature also suggests individualized HF education, a HF-oriented self-care manual, and follow-up phone calls from health care providers facilitate following of treatment plans. ${ }^{22}$ Further enhancement of self-care skills appears promising. ${ }^{23}$ Interventions that improve tactile skills (preparing meals, monitoring weight, etc) and situational decisionmaking skill training (eg, assessing HF symptoms) improve HF self-care behaviors. ${ }^{24,25}$ Involving family members in the plan of care may be useful in addressing long-term HF-related problems and facilitate adherence 
to medications, diet, and symptom monitoring. ${ }^{26,27}$ Family-level interventions also may assist with daily activities, negative moods, and maladaptive coping. ${ }^{23}$ For example, family-based approaches that focus on coping and communication, problem-solving, and managing stress and negative emotions have shown promise, although evidence is limited..$^{28,29}$

Individuals with heart failure continue to experience problems in the home during the second and third months post-hospital discharge. Although treatment regimen and HF symptoms remained a high priority, new or more prevalent problems such as comorbidities, difficulty coping, and depleted resources emerged. Many of these HF problems were interrelated. Future research is needed to expand on the context of these postdischarge problems to identify useful interventions for this largely self-managed patient population.

\section{Patient-Friendly Recap}

- Individuals with heart failure experience new problems in the home over time as they attempt to self-manage this chronic condition following hospital discharge.

- By contacting patients in their homes, the authors learned that heart failure symptoms became more difficult to manage in conjunction with other comorbidities.

- Coping emerged as a new problem as individuals with heart failure dealt with their impending morbidity and its consequences.

- Struggles with financial and social resources also were more prevalent as potential and actual resources were depleted.

\section{Acknowledgments}

Appreciation goes to Kelly Fuller, BSN, for her contribution as a research assistant on this heart failure problem study.

\section{Author Contributions}

Study design: Grant, Graven. Data acquisition and analysis: Grant, Graven. Manuscript drafting: Grant, Graven. Critical revision: Grant, Graven.

\section{Conflicts of Interest}

None.

\section{Funding Sources}

This work was funded by an American Nurse Practitioner Foundation nursing research grant and a Florida State University First Year Assistant Professor grant. The funders had no role in study design, data collection and analysis, decision to publish, or preparation of the manuscript.

\section{References}

1. Ambrosy AP, Fonarow GC, Butler J, et al. The global health and economic burden of hospitalizations for heart failure: lessons learned from hospitalized heart failure registries. $\mathrm{J} \mathrm{Am}$ Coll Cardiol. 2014;63:1123-33. CrossRef

2. Blecker S, Paul M, Taksler G, Ogedegbe G, Katz S. Heart failure-associated hospitalizations in the United States. $J \mathrm{Am}$ Coll Cardiol. 2013;61:1259-67. CrossRef

3. Grant JS, Graven LJ, Fuller K. Problems experienced in the first month after discharge from a heart failure-related hospitalization. J Patient Cent Res Rev. 2018;5:140-8. CrossRef

4. Cameron J, Rhodes KL, Ski CF, Thompson DR. Carers' views on patient self-care in chronic heart failure. $J$ Clin Nurs. 2016;25:144-52. CrossRef

5. Johansson P, Broström A, Sanderman R, Jaarsma T. The course of sleep problems in patients with heart failure and associations to rehospitalizations. J Cardiovasc Nurs. 2015;30:403-10. CrossRef

6. Lee KS, Moser DK, Dracup K. Relationship between self-care and comprehensive understanding of heart failure and its signs and symptoms. Eur J Cardiovasc Nurs. 2018;17:496-504. CrossRef

7. Shumaker SC, Frazier SK, Moser DK, Chung ML. Psychometric properties of the multidimensional scale of perceived social support in patients with heart failure. J Nurs Meas. 2017;25(1):90-102. CrossRef

8. Kraai IH, Vermeulen KM, Hillege HL, Jaarsma T. Perception of impairments by patients with heart failure. Eur J Cardiovasc Nurs. 2016;15:178-85. CrossRef

9. Graven LJ, Gordon G, Bahorski J, Grant Keltner J. Coping partnership intervention improves heart failure self-care confidence and reduces unplanned healthcare utilization. (abstr.) Circulation. 2016;134:A13433.

10. Graven LJ, Grant JS, Gordon G. Symptomatology and coping resources predict self-care behaviors in middle to older age patients with heart failure. Nurs Res Pract. 2015;2015:840240. CrossRef

11. Greenhalgh T, A'Court C, Shaw S. Understanding heart failure; explaining telehealth - a hermeneutic systematic review. BMC Cardiovasc Disord. 2017;17(1):156. CrossRef

12. Graven LJ, Gordon G, Grant Keltner J, Abbott L, Bahorski J. Efficacy of a social support and problem-solving intervention on heart failure self-care: a pilot study. Patient Educ Couns. 2018;101:266-75. CrossRef

13. Colin-Ramirez E, Arcand J, Ezekowitz JA. Dietary selfmanagement in heart failure: high tech or high touch? Curr Treat Options Cardiovasc Med. 2017;19(3):19. CrossRef

14. Johansson P, van der Wal MH, Strömberg A, Waldréus N, Jaarsma T. Fluid restriction in patients with heart failure: how should we think? Eur J Cardiovasc Nurs. 2016;15:301-4. CrossRef

15. Anyanwagu U, Mamza J, Donnelly R, Idris I. Effect of adding GLP-1RA on mortality, cardiovascular events, and metabolic outcomes among insulin-treated patients with type 2 diabetes: a large retrospective UK cohort study. Am Heart J. 2018;196:18-27. CrossRef 
16. Nassif M, Kosiborod M. Effect of glucose-lowering therapies on heart failure. Nat Rev Cardiol. 2018;15:282-91. CrossRef

17. Mentz RJ, Kelly JP, von Lueder TG, et al. Noncardiac comorbidities in heart failure with reduced versus preserved ejection fraction. J Am Coll Cardiol. 2014;64:2281-93. CrossRef

18. Olano-Lizarraga M, Oroviogoicoechea C, Errasti-Ibarrondo B, Saracíbar-Razquin M. The personal experience of living with chronic heart failure: a qualitative meta-synthesis of the literature. J Clin Nurs. 2016;25:2413-29. CrossRef

19. Paturzo M, Petruzzo A, Bertò L, et al. The lived experience of adults with heart failure: a phenomenological study. Ann Ig. 2016;28:263-73. CrossRef

20. Pihl E, Fridlund B, Mårtensson J. Patients' experiences of physical limitations in daily life activities when suffering from chronic heart failure; a phenomenographic analysis. Scand $J$ Caring Sci. 2011;25:3-11. CrossRef

21. Salam AM, Sulaiman K, Al-Suwaidi J, et al. Impact of preventable factors of heart failure on one year rehospitalization; insights from the Gulf CARE Study. (abstr.) Circulation. 2014;130:A11408.

22. Al-Sutari MM, Ahmad MM. Effect of educational program on self-care behaviors and health outcome among patients with heart failure: an experimental study. Int J Evid Based Healthc. 2017; 15:178-85. CrossRef

23. Riegel B, Moser DK, Buck HG, et al. Self-care for the prevention and management of cardiovascular disease and stroke: a scientific statement for healthcare professionals from the American Heart Association. J Am Heart Assoc. 2017;6(9):e006997. CrossRef
24. Dickson VV, Riegel B. Are we teaching what patients need to know? Building skills in heart failure self-care. Heart Lung. 2009;38:253-61. CrossRef

25. Dickson VV, McCarthy MM, Howe A, Schipper J, Katz SM. Sociocultural influences on heart failure self-care among an ethnic minority black population. J Cardiovasc Nurs. 2013;28:111-18. CrossRef

26. Strachan PH, Currie K, Harkness K, Spaling M, Clark AM. Context matters in heart failure self-care: a qualitative systematic review. J Card Fail. 2014;20:448-55. CrossRef

27. Buck HG, Harkness K, Wion R, et al. Caregivers' contributions to heart failure self-care: a systematic review. Eur J Cardiovasc Nurs. 2015;14:79-89. CrossRef

28. Allen JK, Himmelfarb CR, Szanton SL, Bone L., Hill MN, Levine DM. COACH trial: a randomized controlled trial of nurse practitioner/community health worker cardiovascular disease risk reduction in urban community health centers: rationale and design. Contemp Clin Trials. 2011;32:403-11. CrossRef

29. Sebern MD, Woda A. Shared care dyadic intervention: outcome patterns for heart failure care partners. West J Nurs Res. 2012;34:289-316. CrossRef

(C) 2018 Aurora Health Care, Inc. 